\title{
First survey for protosteloid amoebae in South Australia
}

\author{
Tice AK ${ }^{1}$, Fry $\mathrm{NW}^{2}$ and Stephenson $\mathrm{SL}^{2}$ \\ ${ }^{1}$ Department of Biological Sciences, Mississippi State University, Mississippi State, Mississippi 39762 \\ ${ }^{2}$ Department of Biological Sciences, University of Arkansas, Fayetteville, Arkansas 72701
}

Tice AK, Fry NW, Stephenson SL 2014 - First survey for protosteloid amoebae in South Australia. Mycosphere 5(6), 706-710, Doi 10.5943/mycosphere/5/6/1

\begin{abstract}
Samples of ground litter and aerial (dead but still attached plant parts) litter collected from 20 localities in South Australia were examined for the presence of protosteloid amoebae. Fifteen described species were recovered, including seven species that are new records for Australia. In addition, the samples yielded three forms that appear to represent species new to science. Eleven different species were recovered from the 33 samples of ground litter, and 13 species were recorded from the 34 samples of aerial litter.
\end{abstract}

Key words - arid areas - ecology - eumycetozoans - mainland Australia

\section{Introduction}

Protosteloid amoebae (also referred to as protostelids) are simple eumycetozoans (slime molds) with amoeboid trophic cells and simple fruiting bodies in their life cycles. Evidence from recent molecular studies (Shadwick et al. 2009) indicates that these organisms do not constitute a monophyletic group but have been placed together on the basis of sharing a similar morphology. Nevertheless, members of the assemblage, as traditionally circumscribed, occur in similar types of ecological situations and can be isolated in laboratory culture with the use of the same techniques. Protosteloid amoebae were first reported from Australia by Shaw and Olive (1977), who noted the occurrence of three species (Protostelium mycophaga, Cavostelium apophysatum and Schizoplasmodium caveostelioides) that had been isolated some years earlier from samples collected at two different localities (Darwin and Sydney). These same three species were listed by May et al. (2003) in their catalogue and bibliography of Australian fungi. The only other reports of protosteloid amoebae in Australia are those of Spiegel and Stephenson (2000), who listed six species from subantarctic Macquarie Island, and Powers and Stephenson (2006), who reported the results of a survey of 12 study sites in northern Queensland and the Northern Territory. The latter authors recovered 12 species, two of which were apparently undescribed. However, there are no reports of protostelids for most the continent of Australia, which thus remains rather understudied for this group of organisms.

The survey reported in this paper was carried out in South Australia. This state, which makes up the southern central portion of Australia, encompasses some of the most arid areas of the country. Mean annual precipitation is less than $25 \mathrm{~cm}$ over much of the region. The landscape is relatively level, consisting largely of a series of plains and low plateaus (Specht 1972). South Australia is bordered by all of the other major states of mainland Australia, with the Northern Territory to the north, Western Australia to the west, Queensland to the northeast, New South 


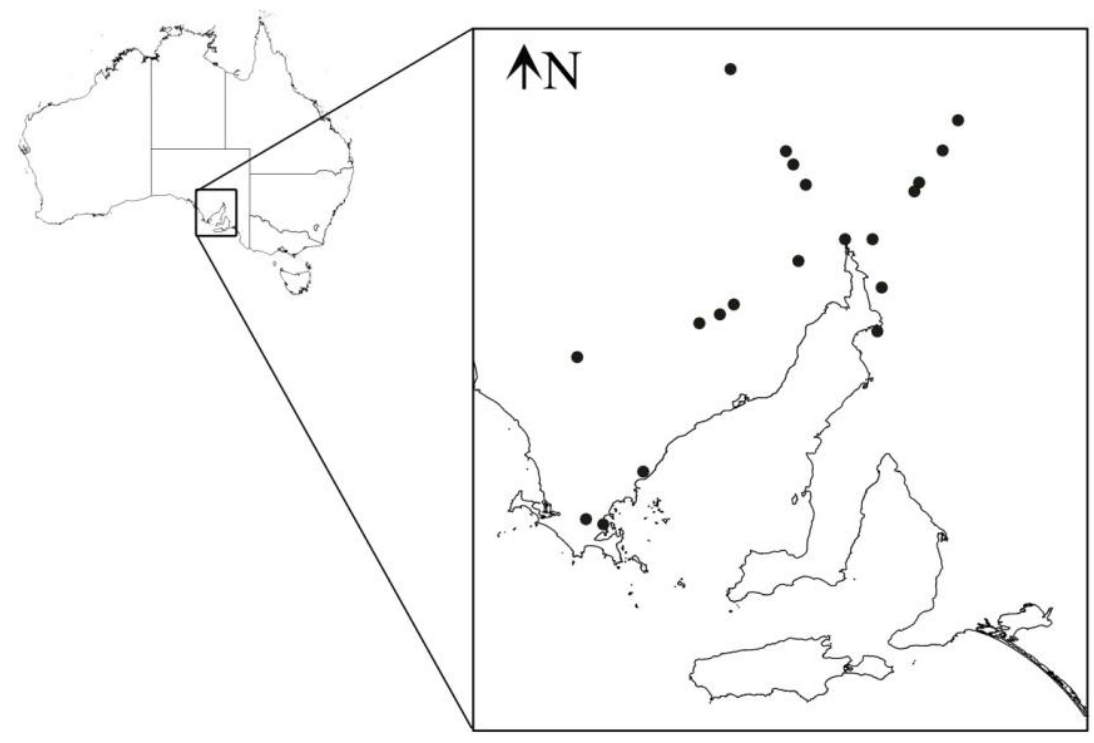

Fig. 1 - Localities (each marked with a black dot) in South Australia from which samples for laboratory isolation of protostelid amoebae were collected.

Wales to the east and Victoria to the southeast. With a total land area of $983,482 \mathrm{~km}^{2}$, it is the fourth largest of Australia's states and territories.

\section{Materials \& Methods}

During the second half of May 2012, 67 samples for laboratory isolation of protosteloid amoebae were collected from 20 different localities in South Australia (Fig. 1). The entire region from which samples were obtained extends between $31.13^{\circ}$ to $34.69^{\circ} \mathrm{S}$ latitude and from $135.65^{\circ}$ to $138.64^{\circ} \mathrm{E}$ longitude. These localities included Eucalyptus woodlands, Acacia woodlands, Callitris woodlands, a streamside community dominated by cattails and rushes, mixed tall shrublands and chenopod shrublands. Samples consisted of either ground litter or aerial litter (dead but still attached plant parts above the ground). These were placed in small paper bags and sent to the University of Arkansas for processing.

Substrates from each sample were broken into pieces roughly $2 \mathrm{~cm}$ in length and plated out onto weak malt yeast agar ( $0.002 \mathrm{~g}$ yeast extract, 0.002 malt extract, $0.75 \mathrm{~g} \mathrm{~K}_{2} \mathrm{HPO}_{4}, 15 \mathrm{~g}$ agar / L distilled $\mathrm{H}_{2} \mathrm{O}$ ). After plating, the surface of each piece of substrate was moistened with a small amount of sterile distilled water. Plates were incubated at room temperature throughout the observational period. Each plate was first examined for the presence of protosteloid amoebae two days after plating, and then every day after for ten days. Species of protosteloid amoebae were identified by fruiting body morphology with the use of a compound light microscope equipped with a 10X objective lens. When possible, species identification was further confirmed by observation of trophic cell and prespore cell morphology. The presence of each species observed on a line of substrate material for a particular sample was recorded. Nomenclature used herein follows Lado (2005-2014).

\section{Results}

The 67 samples processed for protosteloid amoebae yielded a total of 15 described species and three forms that appeared to represent species new to science (Table 1). Seven of the 15 species are new records for Australia. Eleven different species were recovered from the 33 samples of ground litter, and 13 species were recorded from the 34 samples of aerial litter. Eighty-five percent of samples of ground litter were positive for protosteloid amoebae, whereas $76 \%$ of samples of aerial litter were positive. These values are comparable to those obtained by Powers and Stephenson (2006) in their earlier survey. 
Table 1 Occurrence of protosteloid amoebae on samples of litter examined in the present study. Note: $\mathrm{NO}=$ number of occurrences, $\mathrm{PO}=$ percent of the total number of occurrences on the substrate in question, and $\mathrm{TO}=$ total number of occurrences on both substrates.

\begin{tabular}{lrrrrr}
\hline \multicolumn{1}{c}{ Species } & \multicolumn{2}{c}{ Ground } & \multicolumn{2}{c}{ Aerial } & TO \\
\hline Protostelium mycophaga & NO & PO & NO & PO & 45 \\
Schizoplasmodiopsis amoeboidea & 21 & 0.64 & 24 & 0.71 & 11 \\
Schizoplasmodiopsis pseudoendospora & 6 & 0.18 & 5 & 0.15 & 11 \\
Cavostelium apophysatum & 7 & 0.21 & 4 & 0.12 & 7 \\
Protosporangium articulatum & 1 & 0.03 & 6 & 0.18 & 6 \\
Soliformovum irregularis & 3 & 0.09 & 3 & 0.09 & 6 \\
Protosporangium conicum & 3 & 0.09 & 3 & 0.09 & 4 \\
Ceratiomyxella tahitiensis/ & 3 & 0.09 & 1 & 0.03 & 3 \\
$\quad$ Nematostelium gracile & 1 & 0.03 & 2 & 0.06 & \\
Soliformovum expulsum & & & & & \\
Protostelium arachisporum & 3 & 0.09 & 0 & 0.00 & 3 \\
Protostelium pyriformis & 1 & 0.03 & 1 & 0.03 & 2 \\
Unidentified species 2 & 2 & 0.06 & 0 & 0.00 & 2 \\
Echinosteliopsis oligospora & 0 & 0.00 & 2 & 0.06 & 2 \\
Protosporangium bisporum & 0 & 0.00 & 1 & 0.03 & 1 \\
Protostelium okumukumu & 0 & 0.00 & 1 & 0.03 & 1 \\
Schizoplasmodiopsis cavostelioides & 0 & 0.00 & 1 & 0.03 & 1 \\
Unidentified species 1 & 0 & 0.00 & 1 & 0.03 & 1 \\
Unidentified species 3 & 0 & 0.00 & 1 & 0.03 & 1 \\
Total & 1 & 0.03 & 0 & 0.00 & 1 \\
\hline & 52 & & 56 & & 108
\end{tabular}

The three forms that apparently represent species new to science are known only from fruiting body morphology, since all efforts to germinate their spores or subculture the organisms from primary isolation plates were unsuccessful. Based on the resemblance of the three new species to members of the protostelid genus Protosporangium, we consider it likely that they should be assigned to this genus. However, until the organisms in question can be brought into culture and observed in detail, we choose not assign them to any genus at the present time. However, information on the distinguishing features of each is provided below.

\section{Cavostelium apophysatum L.S. Olive}

\section{List of Species}

First reported from Australia by Shaw and Olive (1977) and also recorded by Powers and Stephenson (2006).

Ceratiomyxella tahitiensis L.S. Olive \& Stoian./Nematostelium gracile (L.S. Olive \& Stoian.) L.S. Olive \& Stoian.

Although these two taxa have been recognized as distinct in previous publications, there is now some question that this is the case. Until molecular studies have been carried out, we consider it best to treat them as a single taxon, which is the approach used herein. Nematostelium gracile was first reported from Australia by Powers and Stephenson (2006).

Echinosteliopsis oligospora Reinhardt \& L.S. Olive

First recorded from Australia by Powers and Stephenson (2006).

Protosporangium articulatum L.S. Olive \& Stoian.

New record for Australia.

Protosporangium bisporum L.S. Olive \& Stoian.

New record for Australia. 
Protosporangium conicum W.E. Benn.

New record for Australia.

Protostelium arachisporum L.S. Olive

New record for Australia.

Protostelium mycophaga L.S. Olive \& Stoian.

First reported from Australia by Shaw and Olive (1977) and also recorded by Spiegel and Stephenson (2000) and Powers and Stephenson (2006). Protostelium mycophaga was the first species described for the group of organisms now known as protosteloid amoebae. It appears to be widespread and abundant both worldwide and in Australia, as reflected in the data provided in Table 1.

Protostelium okumukumu Spiegel, J.D. Shadwick \& Hemmes

New record for Australia.

Protostelium pyriformis L.S. Olive \& Stoian.

First reported from Australia by Powers and Stephenson (2006).

Schizoplasmodiopsis amoeboidea L.S. Olive \& K.D. Whitney

New record for Australia. This species and S. pseudoendospora (with 11 records each) were the second most commonly recorded protosteloid amoebae in the present study.

Schizoplasmodiopsis cavostelioides L.S. Olive \& Stoian.

First reported from Australia by Shaw and Olive (1977).

Schizoplasmodiopsis pseudoendospora L.S. Olive, M. Martin, \& Stoian.

First recorded from Australia by Spiegel and Stephenson (2000) and also reported by Powers and Stephenson (2006).

Soliformovum expulsum (L.S. Olive \& Stoian.) Spiegel

New record for Australia.

Soliformovum irregularis (L.S. Olive \& Stoian.) Spiegel

First reported from Australia by Spiegel and Stephenson (2000) and also recorded by Powers and Stephenson (2006).

\section{Undescribed species 1}

This apparently new species was initially mistaken for Protosporangium fragile, since the fruiting body consists of a very long, flexuous stalk with several bends or kinks, a condition similar to that found in P. fragile. Moreover, in one instance several fruiting bodies were observed tangled around one another. This same type of situation is not uncommon in P. fragile (Spiegel et al. 2007). However, spores from the new species were collected from the fruiting bodies and examined at a high magnification. In P. fragile the "spores" are actually sporangia, each of which contains four spores with curved outer walls and flatted surfaces where the spores are in contact with one another in the sporangium (Olive \& Stoianovich 1972). The spores collected from fruiting bodies of the new species were truly spores, each consisting of a single cell rather than a sporangium containing multiple spores.

\section{Undescribed species 2}

This species, designated in our laboratory as "Species J" when recorded previously, has appeared in culture on substrate samples collected in several other regions of the world. However, 
due to the inability to culture the organism, it remains undescribed. The fruiting body of this second undescribed species is similar in size and morphology to Protosporangium articulatum. Like $P$. articulatum, the two spores produced in a fruiting body occur side by side, with the apex of the stalk located between the two spores. However, the stalk of this apparently new species is much thicker and more rigid than that of P. articulatum. The stalk of the former also lacks the articulation located where the stalk is attached to the spores, a feature characteristic of $P$. articulatum. The spores, when observed under high magnification, appear much darker and have a thicker wall than those of $P$. articulatum.

\section{Undescribed species 3}

The third apparently new species closely resembles the "Species J" described above in every respect except that it has a third, much smaller spore located on top of the two larger spores. Approximately half a dozen fruiting bodies appearing on different pieces of substrate material from the same sample were observed to possess this distinctive morphology. Although no fruiting bodies considered as being typical of those produced by "Species J" were found close to those of this apparently third new species, the latter could just be unusual examples of "Species J" with three spores instead of two. Many protostelids occasionally can vary in the number of spores produced (Olive 1975). As such, careful observation of the two different forms in culture along with the appropriate molecular phylogenetic analyses would be needed in order to determine if they represent the same or separate species.

In summary, the records reported herein represent a contribution to what is known about the distribution and ecology of protosteloid amoebae in Australia, where these organisms remain a very understudied group. There is little doubt that additional surveys carried out in other parts of the country would yield new records and possibly also species new to science.

\section{Acknowledgements}

This project was supported in part by ABRS grant 211-06 to SLS. Appreciation is extended to Pam and David Catcheside for providing information on possible collecting sites, and the assistance of Carlos Rojas in preparing the map of South Australia is gratefully acknowledged.

\section{References}

Lado C. 2005-2014 - An online nomenclatural information system of Eumycetozoa. http://www.nomen.eumycetozoa.com (accessed on 14 August 2014).

May TW, Milne J, Shingles S, Jones RH. 2003 - Fungi of Australia, Volume 2B: Catalogue and Bibliography of Australian Fungi 2, Basidiomycota p.p. \& Myxomycota p.p. ABRS, Canberra/CSIRO Publishing, Melbourne.

Olive LS. 1975 - The Mycetozoans. Academic Press, Inc., New York.

Olive LS, Stoianovitch C. 1972 - Protosporangium: a new genus of protostelids. The Journal of Protozoology 19, 563-571.

Powers DM, Stephenson SL. 2006 - Protostelids from tropical forests, woodlands and deserts of Australia. Mycologia 98, 218-222.

Shadwick LL, Spiegel FW, Shadwick JD, Brown MW, Silberman JD. $2009-$ Eumycetozoa $=$ Amoebozoa?: SSUrDNA phylogeny of protosteloid slime molds and its significance for the amoebozoan supergroup. PLoS One. 25, 4(8):e6754. doi: 10.1371/journal.pone.0006754.

Shaw DE, Olive LB. 1977 - A rare protostelid (Mycetozoa) recorded in Australia. Proceedings of the Linnean Society of New South Wales 102, 58-59.

Specht RL. 1972 - The Vegetation of South Australia, $2^{\text {nd }}$ ed. A. B. James, Government Printer, Adelaide, Australia.

Spiegel FW, Stephenson SL. 2000 - Protostelids of Macquarie Island. Mycologia 92, 49-852.

Spiegel FW, Shadwick JD, Lindley LA, Brown MW, Nderitu G. 2007 - A Beginners's Guide to Identifying the Protostelids. http://slime-mold.uark.edu/pdfs/Handbook1_3rd.pdf. 